\title{
Micro Pre-concentration and Separation of Metal Ions Using Microchip Column Packed with Magnetic Particles Immobilized by Aminobenzyl Ethylenediaminetetraacetic Acid
}

\author{
Y. H. Kim, G. Y. Kim, and H. B. Lim* \\ Department of Chemistry, CPEM, Dankook University, Yongin, Gyeonggi 448-701, Korea. *E-mail: plasma@dankook.ac.kr \\ Received September 29, 2009, Accepted February 4, 2010
}

\begin{abstract}
Magnetic beads (Dynabeads ${ }^{\circledR}$ ) embedded in $\sim 1$ micron size polystyrene beads bearing surface carboxylic acid groups were modified with aminobenzyl ethylenediaminetetraacetic acid (ABEDTA) to concentrate or separate metal ions using $\mathrm{pH}$ gradients on micro and nano scales. The immobilization of ABEDTA was achieved by amide formation. The presence of the metal chelating functional group in the fully deprotonated form was confirmed by FT-IR. The chelation efficiency of beads was tested by determining metal ions in supernatant using GFAAS when $\mathrm{pH}$ gradients from 3 to 7 . Mixtures of $\mathrm{Cu}$ and $\mathrm{Mg}$ and of $\mathrm{Cd}$ and $\mathrm{Mn}$ (at $10 \mathrm{ng} / \mathrm{mL}$ of metal) were separated as the difference in formation constant with the functional group of ABEDTA. The separation was repeated twice with relative standard deviation of $<18 \%$. A polydimethylsiloxane (PDMS) microchip column packed with EDTA-coated magnetic beads was optimized to concentrate metal ion for practical applications by eluting a $\mathrm{Cu}$ solution of micro scale at $\mathrm{pH} 3$.
\end{abstract}

Key Words: Magnetic bead, Iron oxide, Metal separation and concentration, Immobilization of EDTA, Polydimethylsiloxane microchip

\section{Introduction}

Magnetic particles have been exploited widely as for cell sorting and labeling, biomedical and chemical separations, magnetic resonance imaging, and for the purification of proteins and DNA, because they have low toxicities and are easily handled. ${ }^{1-10}$ The majority of studies on magnetic particles have focused on biological or clinical applications and interactions with bio-functional groups. Nevertheless, several studies ${ }^{11-17}$ have examined interactions between magnetic beads and metal ions due to the important roles played by metals in environmental and biological systems. For application, those magnetic particles in nano or micro size were coated by a bifunctional polymer layer used as extractants for organic compounds. Reported extractants among the polymer were organic organophosphorus species or organic acids, such as octylphenyl- $N, N$-didsobutylcarbamoylmethyl phosphine oxide (CMPO), tributylphosphate (TBP), or bis(2,4,4-trimethylpentyl) phosphinic acids (Cyanex). ${ }^{11,18,19}$ However, the application of those magnetic beads was mostly focused on metal removal, not metal separation or specific metal concentration, though it is becoming more important in the context of metal elimination and concentration. For example, ethylenediaminetetraacetic acid (EDTA) has often been used to elute or eliminate interfering metal ions in order to improve the analytical performance when biological samples are analyzed by liquid chromatography-mass spectrometry (LC-MS). ${ }^{20-25}$ Furthermore, if trace metal ion analysis is required in biological samples, a concentration process is often required prior to, for example, inductively coupled plasma-mass spectrometer (ICPMS), ${ }^{26-32}$ graphite furnace atomic absorption spectrometer (GFAAS), ${ }^{33-36}$ and ESI-MS. ${ }^{37}$ Moreover, magnetic beads bearing surface chelating ligands could be used to concentrate trace metal ions from small sample volumes. For example, iron oxide magnetic beads with nitrilotriacetic acid (NTA) immobilized on their surfaces have been used as affinity probes for calcium ions in dairy drinks, and EDTA has been used to extract metal ions chelated by NTA. ${ }^{37}$ Moreover, we considered if EDTA could be directly immobilized on magnetic bead surfaces that the beads could be collected using magnets for reuse. In addition, since EDTA complexes have different formation constants and $\mathrm{pH}$ dependences, we considered that magnetic beads could also be used as a chromatographic resin to separate metal ions.

In this work, we found a means of directly functionalizing EDTA on the surfaces of magnetic beads using aminobenzyl EDTA. We also demonstrate the complexation and separation of metal ions in micro scale using these bead in batch mode and in the channels of poly(dimethylsiloxane) (PDMS) microchips under continuous flow conditions.

\section{Experimental}

Reagents. Magnetic particles embedded in polystyrene beads of diameter $1 \mu \mathrm{m}$ (Dynabeads ${ }^{\mathbb{R}}$ ), were purchased from Invitrogen Dynal AS (Oslo, Norway). Since the surface of Dynabeads (Myone ${ }^{\mathrm{TM}}$ Carboxylic acid) was functionalized with $-\mathrm{COOH}$, ABEDTA (1-(4-aminobenzyl) ethylenediamine- $N-N-N^{\prime}-N^{\prime}$-tetracetic acid, $90 \%$, Fluka) can form amide covalent bond with the beads for metal chelation. For this surface modification, MES (2-morpholinoethansulfonic acid monohydrate, 99\%, Merck) of pH 6 in aqueous solution, NHS ( $N$-hydroxy succinimide, $98 \%$ ), EDC ( $N$-(3-dimethyl amino propyl)- $N$-ethyl carbodiimide hydrochloride, $99 \%$ ) were purchased from Sigma-Aldrich. For metal-EDTA complexation, $10 \mathrm{ng} / \mathrm{mL}$ metal solutions were prepared daily in nitric acid (DongWoo Fine Chem., Iksan, Korea) at $\mathrm{pH}$ ranges of 3 to 7 from stock solutions of metals (10 $\mu \mathrm{g} / \mathrm{mL})$ in $0.1 \%(\mathrm{v} / \mathrm{v})$ nitric acid. Standard solutions of metals 


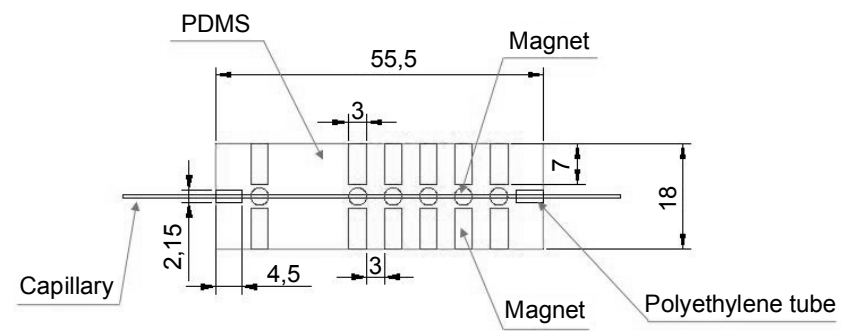

Figure 1. Schematic of a microchip column packed with magnetic beads using magnetic bars.

were purchased from Sigma-Aldrich.

Unless stated otherwise, all water used was of $18.2 \mathrm{M} \Omega$ and distilled and deionized using a purifier (Millipore-Q, USA).

Instrument. A graphite furnace atomic absorption spectrometer (GFAAS, Solaar GF95, Thermo Elemental, UK) was used to determine the concentrations of metal ions. Operating conditions for each element, such as lamp current, slit width, PMT voltage, wavelength, temperature programming conditions, were set according to the manufacturer's instructions. Sample volumes of $20 \mu \mathrm{L}$ were injected throughout the study.

Fourier Transform-Infrared Spectrometry (FT-IR, Spectrum 100 , Perkin-Elmer, USA) was used to identify ABEDTA immobilized on bead surfaces.

Magnet bead column. A PDMS chip with rod-type magnets ( $3 \mathrm{~mm}$ diameter $\times 7 \mathrm{~mm}$ in length, 3000 gauss) was fabricated to a total chip size of $16 \times 16 \times 55.5 \mathrm{~mm}$ (Fig. 1). Fused silica capillary tubing of i.d. $365 \mu \mathrm{m}$ was inserted into the central channel of the chip. Five sets of magnets, each set comprised of 4 magnet rods, were embedded in the $3 \mathrm{~mm}$ space around the central channel, and another set of 4 rods was placed $13.5 \mathrm{~mm}$ downstream of the capillary. This geometry provided enough magnetic force to hold the magnetic beads for packing in the capillary tubing. These chips with the bead column can be easily prepared and replaced by a sequence of coping PDMS chip, inserting magnetic bars and then flowing magnetic beads for packing. Four PDMS microchips with bead column were prepared for the measurement.

Coupling of ABEDTA. To couple ABEDTA to the bead surface with carboxylic groups, a two-step coating procedure was employed (Fig. 2). Briefly, $300 \mu \mathrm{L}$ (about $3 \mathrm{mg}$ beads) of Dynabeads were washed twice with an equal volume of $25 \mathrm{mM}$ MES buffer ( $\mathrm{pH}$ 6) for $10 \mathrm{~min}$. EDC $(50 \mathrm{mg})$ and NHS $(50 \mathrm{mg})$ were dissolved in $1 \mathrm{~mL}$ of $25 \mathrm{mM}$ MES, respectively. Then, the prepared EDC and NHS solutions (50 $\mu \mathrm{L}$ of each) were added to beads and incubated for $30 \mathrm{~min}$ with gentle shaking. After centrifugation, supernatants were removed and the activated beads were washed several times with $300 \mu \mathrm{L}$ of MES buffer. ABEDTA ( $1 \mathrm{mg}$ ) dissolved in $25 \mathrm{mM}$ MES of $60 \mu \mathrm{L}$ was then added to the beads followed by MES $(40 \mu \mathrm{L})$. Beads were then vortexed to ensure good mixing, and incubated for $30 \mathrm{~min}$. Supernatant was decanted while magnets held the beads in place. If necessary, ethanolamine $(0.05 \mathrm{mM})$ diluted with $1 \times$ PBS (Phosphate Buffer in Saline, Ambion, $\mathrm{pH}$ 7.4) buffer was added and incubated for 60 min with mild shaking to block the functionality of non-reacted carboxylic acid groups. Beads were then washed

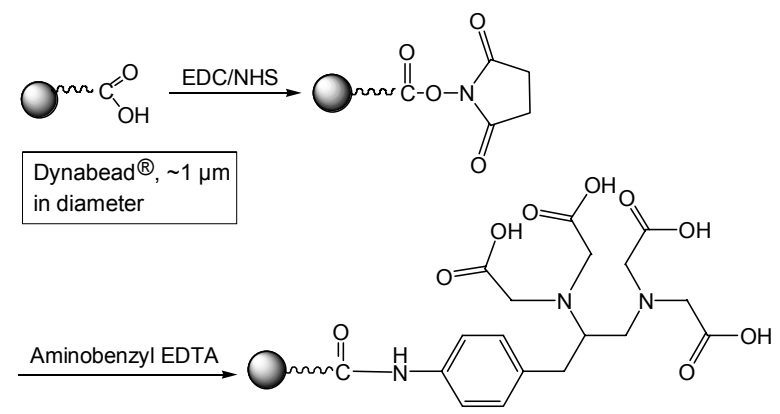

Figure 2. EDTA modification of - $\mathrm{COOH}$ functional groups on Dynabead $^{\mathbb{B}}$ surfaces of $\sim 1 \mu \mathrm{m}$ in diameter: $(1)$ activated Dynabead ${ }^{\mathbb{B}}$ with carbodiimide and (2) ABEDTA-immobilized beads.

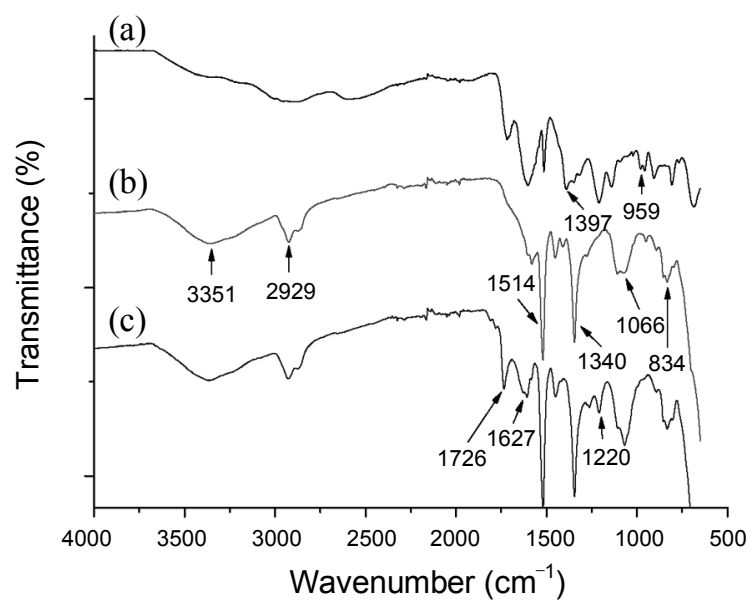

Figure 3. Comparison of the FT-IR spectra of (a) ABEDTA, (b) - $\mathrm{COOH}$ beads (naïve Dynabeads ${ }^{\circledR}$ ), and (c) ABEDTA-immobilized beads.

with PBS buffer 4 times, re-dispersed, and stored in a freezer at $2-8^{\circ} \mathrm{C}$. ABEDTA-coated beads were washed with nitric acid (pH 3) prior to use. Final bead volume was adjusted to $300 \mu \mathrm{L}$ at the required $\mathrm{pH}$. Coated beads were placed in a polyethylene (PE) vial and mixed with metal ions by vortexing for $30 \mathrm{~min}$. Metal ions in supernatants were quantified by GFAAS to determine complexation efficiency.

\section{Results and Discussion}

Identification of ABEDTA. Surface carboxylic groups were activated by adding carbodiimide to react with an amine group for ABEDTA coating on Dynabeads. ${ }^{38}$ The immobilized ABEDTA was characterized by FT-IR spectrophotometry. Although difficulty was expected to differentiate ABEDTA coated from uncoated beads in the IR spectrum since Dynabeads contained similar functional groups, such as, carboxylate and benzene, some functional groups produced specific absorption bands.

Fig. 3 (a, b, c) shows FT-IR spectra of ABEDTA only (a), control Dynabeads (b), and ABEDTA-immobilized beads (c), respectively. FT-IR spectra of immobilized ABEDTA on magnetic beads (c) contained specific absorption bands of the functional groups of ABEDTA (a). For instance, strong absorption 
(a)

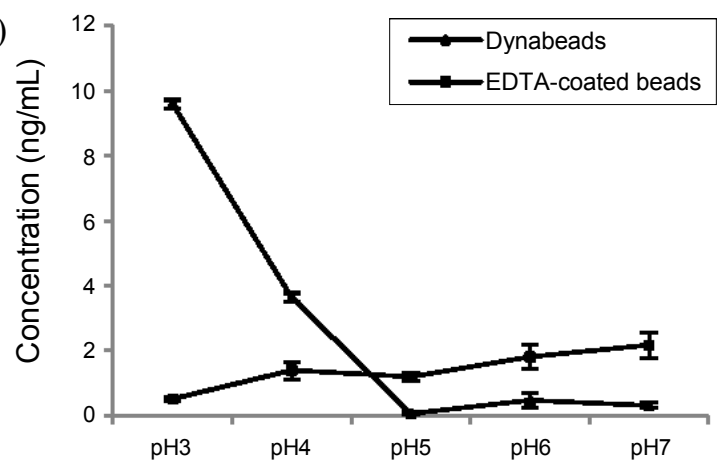

(c)

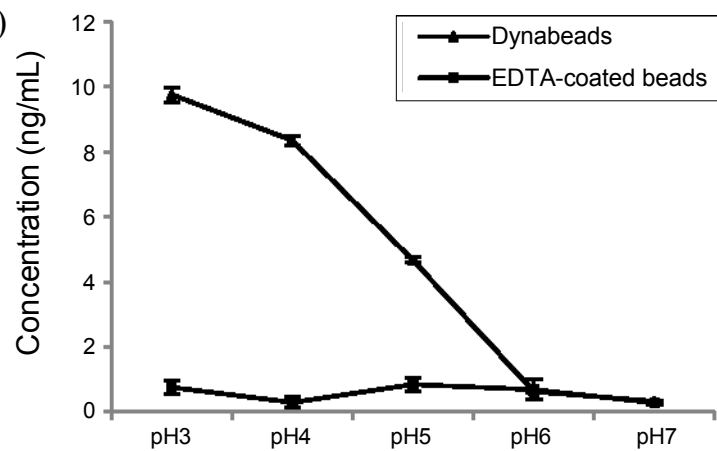

(b)

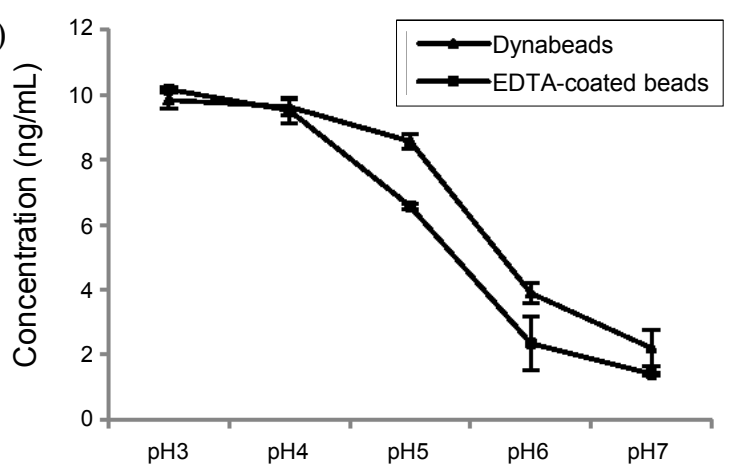

(d)

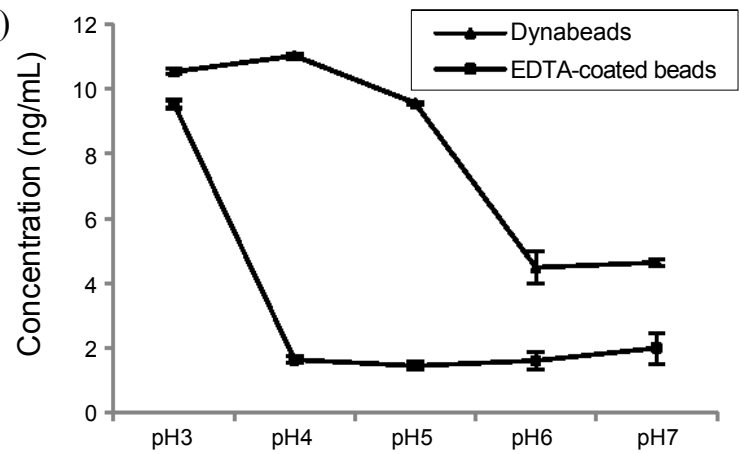

Figure 4. Concentration change of metal ions when $10 \mathrm{ng} / \mathrm{mL}$ solutions were mixed with -COOH beads (naïve Dynabeads ${ }^{\circledR}$ ) and ABEDTA surface modified beads (ABEDTA beads) at different $\mathrm{pH}$ values: (a) $\mathrm{Cu}$, (b) $\mathrm{Mg}$, (c) $\mathrm{Cd}$, and (d) $\mathrm{Mn}$.

peaks appeared at 1726 and $1627 \mathrm{~cm}^{-1}$, which represented paired $\mathrm{C}=\mathrm{O}$ stretching frequencies. Similarly, the small peak at 1397 $\mathrm{cm}^{-1}$ represented the characteristic aromatic $\mathrm{C}=\mathrm{C}$ stretching mode of the benzene ring of ABEDTA, although a similar $\mathrm{C}=\mathrm{C}$ stretch at $1514 \mathrm{~cm}^{-1}$ was attributed to the styrene group of Dynabeads. The $\mathrm{C}-\mathrm{N}$ peak at $1220 \mathrm{~cm}^{-1}$ was also attributed to ABEDTA. Weak bands at $959 \mathrm{~cm}^{-1}$ represented benzyl C-H bending, and were not observed for naïve Dynabeads (b). These data demonstrate the presence of ABEDTA on Dynabeads. The peaks at $3351 \mathrm{~cm}^{-1}, 2929 \mathrm{~cm}^{-1}, 1340 \mathrm{~cm}^{-1}, 1066 \mathrm{~cm}^{-1}$ and $834 \mathrm{~cm}^{-1}$ were common to both ABEDTA functionalized beads and Dynabeads.

Metal complex. The magnetic beads immobilized with ABEDTA can hold metal ions by the formation of metal complex. The formation constants of these complexes depend on $\mathrm{pH}$, which determines the protonation level and the nature of the equilibrium between bound and free metal ions.

The ability of the functionalized beads to complex $\mathrm{Cu}, \mathrm{Mg}$, $\mathrm{Cd}$, and $\mathrm{Mn}$ ions was tested using batch type reactions, during the dispersed beads were mixed with metal ions in a mixing tube at different $\mathrm{pH}$ values. The concentrations of metal ions in supernatants before and after mixing were determined by GFA$\mathrm{AS}$, and analytical results after background subtraction are shown in Fig. 4. The error bars in the figures represented the standard deviations of two measurements. Since-COOH on Dynabeads can also complex with metal ions, metal ion concentrations were also determined for these beads. At pH 3, the concentrations of $\mathrm{Cu}$ in supernatant in the presence of ABEDTA beads were significantly reduced, but no reduction was observed for -COOH beads (naïve Dynabeads), as shown in Fig. 4(a), when
$10 \mathrm{ng} / \mathrm{mL} \mathrm{Cu}$ was mixed with $50 \mu \mathrm{L}$ of beads in solution. When the $\mathrm{pH}$ was increased to 4 , about $40 \%$ of the $\mathrm{Cu}$ remained in the supernatant for $-\mathrm{COOH}$ bead, and at $\mathrm{pH}$ values of $>5$, almost no difference was observed between the two. In the case of $\mathrm{Mg}$, as shown in Fig. 4(b), Mg ion concentrations in solution dropped from $\mathrm{pH} 5$ for both bead types, and concentration in solution reduced to $\sim 25-38 \%$ at $\mathrm{pH} 5$ - 6 while no difference was observed between the two. However, this reduction of Mg concentration in solution was not as substantial as that of $\mathrm{Cu}$. About 18 to $21 \%$ of $\mathrm{Mg}$ remained in solution even at $\mathrm{pH}$ 7. The interaction between the $\mathrm{Cd}$ ion and the ABEDTA beads was similar to that of $\mathrm{Cu}$ except that the reduction in $\mathrm{Cd}$ concentration for - $\mathrm{COOH}$ beads was not as large as that of $\mathrm{Cu}$. In the case of $\mathrm{Mn}$, concentration in solution reduced for ABEDTA beads at $\mathrm{pH} 4$ or higher, whereas for - $\mathrm{COOH}$ beads $\mathrm{Mn}$ behaved in the same manner as $\mathrm{Mg}$.

Metal ion separations. Two mixtures of ions in solutions at $10 \mathrm{ng} / \mathrm{mL}$, i.e., $\mathrm{Mg}$ and $\mathrm{Cu}$ or $\mathrm{Mn}$ and $\mathrm{Cd}$, were prepared. $\mathrm{ABE}-$ DTA-coated beads were added to these mixtures for $10 \mathrm{~min}$. ABEDTA beads were removed from solution using a magnet. The metal ions remaining in solution were determined by GF$\mathrm{AAS}$, and their concentrations were plotted versus solution $\mathrm{pH}$, as shown in Fig. 5(a) for $\mathrm{Cu}$ and $\mathrm{Mg}$, and in (b) for $\mathrm{Cd}$ and $\mathrm{Mn}$. For GFAAS measurements, $20 \mu \mathrm{L}$ aliquots of supernatant were injected; other operating conditions were according to the manufacturer's instructions, which included the use of a matrix modifier. As shown in Fig. 5(a), Mg and $\mathrm{Cu}$ showed different affinities for ABEDTA beads (Fig. 4(a) and (b)), i.e., Cu showed stronger affinity than $\mathrm{Mg}$ throughout the $\mathrm{pH}$ range 3-7. Because the solution concentration of $\mathrm{Mg}$ began to reduce from $\mathrm{pH}$, the 
(a)

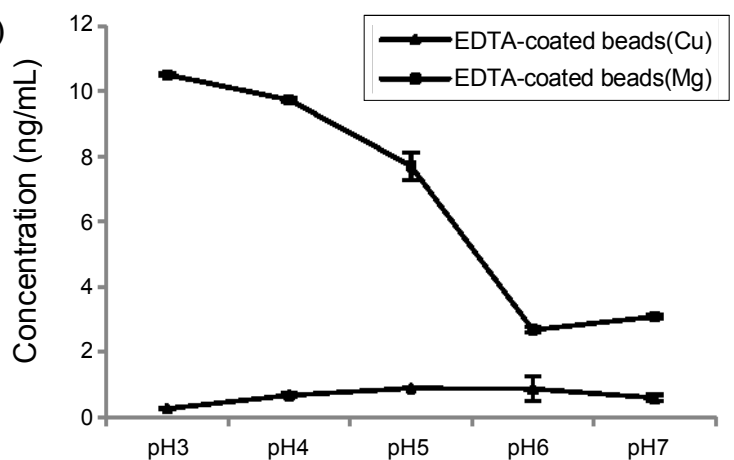

(b)

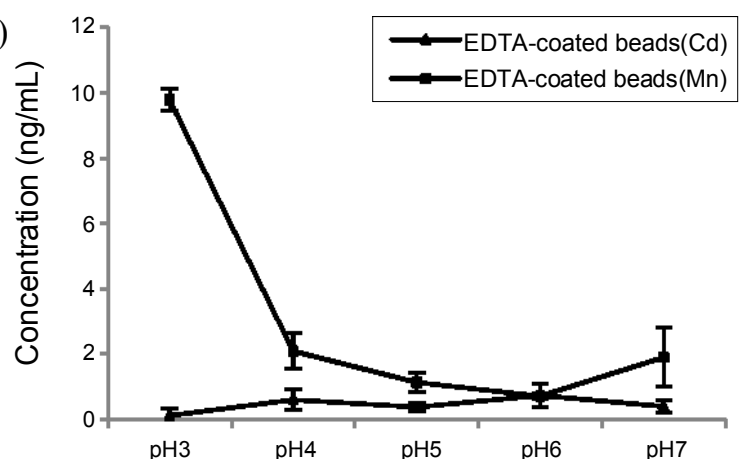

Figure 5. Solution concentration changes of $\mathrm{Cu}$ and $\mathrm{Mg}$ (a) and $\mathrm{Cd}$ and $\mathrm{Mn}(\mathrm{b})$ in supernatants when solutions containing $10 \mathrm{ng} / \mathrm{mL}$ of metal ions were mixed with ABEDTA beads.

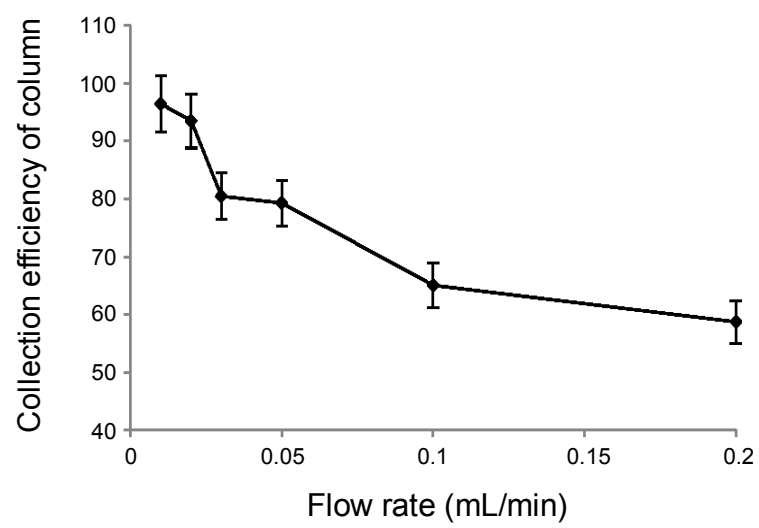

Figure 6. Solution concentration changes of the $\mathrm{Cu}$ ion (initial solution concentration $3 \mathrm{ng} / \mathrm{mL}$ ) versus flow rate in a capillary column packed with magnetic beads.

two metals were separable from between $\mathrm{pH} 3$ and 4 without any $\mathrm{Mg}$ loss. Similarly, since the affinity of $\mathrm{Cd}$ to ABEDTA was slightly higher than that of Mn, as shown in Fig. 5(b), Cd was separated from $\mathrm{Mn}$ at $\mathrm{pH} 3$.

Metal concentrations and the PDMS chip. Magnetic beads were packed in a fused silica capillary column which was inserted in the central channel of PDMS microchip as shown in Fig. 1. Magnetic bars were embedded as close to the capillary column to secure beads at the microchip channel. The packed column was washed with nitric acid at $\mathrm{pH} 3.0$ prior to use. Since the ability of ABEDTA to separate metal ions is strongly dependent on $\mathrm{pH}$ and flow rate, the flow rate of the eluent was optimized at $\mathrm{pH}$ 3. As shown in Fig. 6, the number of $\mathrm{Cu}$ ions entrapped by the microchip column at a solution concentration of $3 \mathrm{ng} / \mathrm{mL}$ reduced with flow rate. A maximum efficiency of $\sim 97 \%$ for $\mathrm{Cu}$ ion entrapment was obtained at a flow rate of $0.01 \mathrm{~mL} / \mathrm{min}$. On increasing the flow rate ten folds, the efficiency dropped to $65 \%$, indicating that flow through the column influences the efficiency of the column. Furthermore, magnetic beads detached from the channel at high flow rates. In this experiment, the calculated fluidic force acting on beads in the microchip channel at a flow rate of $0.01 \mathrm{~mL} / \mathrm{min}$ was about 500 times smaller than the magnetic force applied by the magnetic bars. To remove beads from the capillary column, the magnets were simply re- moved under flow conditions.

In conclusion, magnetic beads bearing surface - $\mathrm{COOH}$ functional groups were modified with ABEDTA and then used to concentrate or separate metal ions from solution in micro scale. The stabilities of the magnetic bead columns formed were dependent on flow rate and magnetic force, and when flow rates were too high, magnetic beads were displaced from the column and column packing efficiencies were disrupted. Accordingly, properly optimized flow rates are required for efficient operation.

Acknowledgments. This work was supported by Internal Research Fund of Dankook University (2009).

\section{References}

1. Kohler, N.; Fryxell, G. E.; Zhang, M. J. Am. Chem. Soc. 2004, 126, 7206-7211.

2. Gupta, A. K.; Curtis, A. S. G. Biomaterials 2004, 25, 3029-3040.

3. McCloskey, K. E.; Chalmers, J. J.; Zborowski, M. Anal. Chem. 2003, 75, 6868-6874.

4. Osaka, T.; Matsunaga, T.; Nakanishi, T.; Arakaki, A.; Niwa, D.; Iida, H. Anal. Bioanal. Chem. 2006, 384, 593-600.

5. Pankhurst, Q. A.; Connolly, J.; Jones, S. K.; Dobson, J. J. Phys. D: Appl. Phys. 2003, 36, R167-R181.

6. Atia, A. A.; Donia, A. M.; Shahin, A. E. Sep. Purif. Techno. 2005, 46, 208-213.

7. Shieha, D. B.; Chengb, F. Y.; Sub, C. H.; Yehb, C. S.; Wuc, M. T.; Wud, Y. N.; Tsaie, C. Y.; Wue, C. L.; Chenf, D. H.; Choug, C. H. Biomaterials 2005, 26, 7183-7191.

8. Taylor, J. I.; Hurst, C. D.; Davies, M. J.; Sachsinger, N.; Bruce, I. J. J. Chromatogr. A 2000, 890, 159-166.

9. Ma, Z.; Guana,Y.; Liua, H. J. Magn. Magn. Mater. 2006, 301, 469-477.

10. Sun, J.; Zhou, S.; Hou, P.; Yang, Y.; Weng, J.; Li, X.; Li, M. J. Biomed. Mater. Res. A 2007, 80, 333-341.

11. Ngomsik, A. F.; Bee, A.; Draye, M.; Cote, G.; Cabuil, V. C. R. Chimie. 2005, 8, 963-970.

12. Hu, J.; Chen, G.; Lo, I. M. C. Water. Res. 2005, 39, 4528-4536.

13. Hu, J.; Lo, I. M. C.; Chen, G. Sep. Purif. Techno. 2007, 56, 249-256.

14. Liu, W. T. J. Biosci. Bioeng. 2006, 102, 1-7.

15. Xu, C.; Xu, K.; Gu, H.; Zhong, X.; Guo, Z.; Zheng, R.; Zhang, X.; Xu, B. J. Am. Chem. Soc. 2004, 126, 3392-3393.

16. Ma, Z.; Guan, Y.; Liu, H. J. Magn. Magn. Mater. 2006, 301, 469477

17. Xu, X.; Deng, C.; Gao, M.; Yu, W.; Yang, P.; Zhang, X. Adv. Mater. 2006, 18, 3289-3293. 
18. Kaminski, M. D.; Landsberger, S.; Nunez, L.; Vandegrift, G. F. Separation Sci. Technol. 1997, 32, 115-126.

19. Kaminski, M. D.; Nunez, L.; Visser, A. E. Separation Sci. Technol. 1999, 34 (6-7), 1103-1120.

20. Sun, B.; Zhal, F. J.; Lombi, E.; McGrath, S. P. Environ. Pollut. 2001, 113, 111-120.

21. Jeon, C.; Park, J. Y.; Yoo, Y. J. Water Res. 2002, 36, 1814-1824.

22. Chen, C. Y.; Chiang, C. L.; Huang, P. C. Sep. Purif. Techno. 2006, 50, 15-21.

23. Macc, C.; Sold, L.; Favaro, G.; Pastore, P. Talanta 2007, 72, 655662.

24. Vatta, L. L.; Kramer, J.; Koch, K. R. Sep. Purif. Techno. 2007, 42, 1985-2002.

25. Pastor, J.; Aparicio, A. M.; Maroto, A. G.; Hernández, A. J. Sci. Total. Environ. 2007, 378, 114-118.

26. Begerow, J.; Turfeld, M.; Dunemann, L. J. Anal. At. Spectrom. 2000, 15, 347-352.

27. Huang, C.; Beauchemin, D. J. Anal. At. Spectrom. 2003, 18, 951952.
28. Bocca, B.; Alimonti, A.; Petrucci, F.; Violante, N.; Sancesario, G.; Forte, G.; Senofonte, O. Spectrochim. Acta B 2004, 59, 559-566.

29. Krishna, M. V. B.; Arunachalam, J. Anal. Chim. Acta 2004, 522, 179-187.

30. Sohrin, Y.; Urushihara, S.; Nakatsuka, S.; Kono, T.; Higo, E.; Minami, T.; Norisuye, K.; Umetani, S. Anal. Chem. 2008, 80, 62676273.

31. Su, C. K.; Li, T. W.; Sun, Y. C. Anal. Chem. 2008, 80, 6959-6967.

32. Huang, C.; Hu, B. Spectrochim. Acta Part B 2008, 63, 437-444.

33. Begerow, J.; Turfeld, M.; Dunemann, L. J. Anal. At. Spectrom. 2000, 15, 347-352.

34. Divrikli, Ü.; Elçi, L. Anal. Chim. Acta 2002, 452, 231-235.

35. Felipe-Sotelo, M.; Andrade, J. M.; Carlosena, A.; Prada, D. Anal. Chem. 2003, 75, 5254-5261.

36. Othman, A. M.; Shahawi, M. S. E.; Azeem, M. A. Anal. Chim. Acta 2006, 555, 322-328.

37. Wu, Y. T.; Chen, Y. C. Rapid Communications in Mass Spectrometry 2006, 20, 1995-1999.

38. Studer, M.; Meares, C. F. Bioconjugate Chem. 1992, 3, 420-423. 